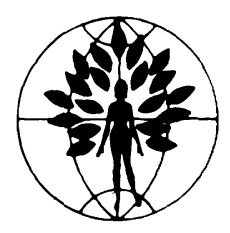

\title{
Article
}

\section{Characteristics of fetal heart rate tracings prior to uterine rupture ${ }^{\text {is }}$}

\author{
A.W. Ayres*, T.R.B. Johnson, R. Hayashi \\ Department of Obstetrics \& Gynecology, MFM Division, University of Michigan, Ann Arbor, MI, USA
}

Received 28 March 2001; received in revised form 24 May 2001; accepted 31 May 2001

\begin{abstract}
Objective: To identify the fetal heart rate patterns that occurred in a 2 -h period of time preceding uterine rupture. Methods: The fetal monitor strips and the medical records of patients with a confirmed diagnosis of uterine rupture were reviewed. These patients delivered at the University of Michigan Hospital from January 1, 1985 to December 31, 1999 and were $\geq 28$ weeks gestational age. Asymptomatic uterine scar dehiscences were excluded. The weeks of gestation, the number of cesarean sections, the surgical findings, and the maternal complications were obtained from the review of the maternal records. The fetal monitor strips for the $2 \mathrm{~h}$ preceding the uterine rupture were analyzed, and the fetal heart rate patterns were classified. Results: During the study period, there were 11 patients identified with uterine rupture. Seven of the $11(64 \%)$ had operative or post-operative complications. There were no maternal deaths. Review of the eight fetal heart rate tracings available revealed $7 / 8(87.5 \%)$ with recurrent late decelerations and $4 / 8(50 \%)$ with terminal bradycardia. All four of the patients with fetal bradycardia were preceded by recurrent late decelerations (100\%). Conclusions: The most common fetal heart rate abnormalities that occurred prior to uterine rupture were recurrent late decelerations and bradycardia. The appearance of recurrent late decelerations may be an early sign of impending uterine rupture. (C) 2001 International Federation of Gynecology and Obstetrics. All rights reserved.

Keywords: Fetal monitor tracings; Uterine rupture

\footnotetext{
Disclaimer: This article was written by CDR Allen Ayres, MC, USN, while a Fellow at the University of Michigan training in Maternal-Fetal-Medicine. The views expressed in this article are those of the author and do not reflect the official policy or position of the Department of the Navy, Department of Defense, nor the US Government.

* Corresponding author. Tel.: +1-734-764-1406; fax: +1-734-647-1006.

E-mail address: awayres@med.umich.edu (A.W. Ayres).
} 


\section{Introduction}

Rupture of the pregnant uterus, although infrequent, is a catastrophic complication of pregnancy that can result in mortality or serious morbidity of both the mother and the fetus. Uterine rupture can occur in a previously scarred uterus or, more rarely, in a non-scarred uterus. Even though the incidence of true uterine rupture is uncommon, $0.03-0.04 \%$, [1,2] it still remains a difficult diagnostic and management challenge for the clinician.

The most common sign of uterine rupture is a non-reassuring fetal heart rate tracing with variable decelerations that may progress to late decelerations, bradycardia, or undetectable fetal heart rate $[3,4]$. Other signs include abdominal pain, vaginal bleeding, loss of station of the presenting fetal part, hypovolemia, and shock $[3,5]$. However, if these signs appear, they occur late in the clinical presentation of uterine rupture. Frequently, the diagnosis of uterine rupture is confirmed at the laparotomy.

The purpose of our study is to identify the type(s) of fetal heart rate pattern(s) that occurred in a 2-h period of time preceding uterine rupture.

\section{Materials and methods}

Approval for the study was obtained from the Institutional Review Board for Human Subject Research at the University of Michigan Medical School. This is a retrospective study in which the fetal monitor strips and the medical records of all patients with the confirmed diagnosis of uterine rupture who delivered at the University of Michigan Hospital from January 1, 1985 through December 31, 1999 were reviewed. The definition of uterine rupture by Plauché [5] was used: 'complete separation of the wall of the pregnant uterus, with or without expulsion of the fetus, which endangered the life of the mother and/or fetus'. Asymptomatic uterine scar dehiscences were excluded. Only those patients who were $\geq 28$ weeks of gestation and met the above definition were included in the study. The following information was recorded upon review of the patient's medical record: (1) weeks of gestation; (2) number of cesarean sections; (3) surgical findings/operation; and (4) maternal complications. Since the primary aim of the study was to analyze the fetal heart rate patterns prior to uterine rupture, the neonatal data were not reviewed.

The fetal monitor strips for the $2 \mathrm{~h}$ preceding the uterine rupture were analyzed, and the fetal heart rate patterns were classified as defined by the National Institute of Child Health and $\mathrm{Hu}-$ man Development Research Planning Workshop [6]. The following definitions were used. (1) Bradycardia - baseline fetal heart rate is $<110$ beats $/$ min lasting for $\geq 10 \mathrm{~min}$. (2) Tachycardia - baseline fetal heart rate is $>160$ beats $/ \mathrm{min}$ lasting for $\geq 10 \mathrm{~min}$. (3) Late deceleration - a visually apparent gradual decrease (defined as onset of deceleration to nadir $\geq 30 \mathrm{~s}$ ) in the fetal heart rate with return to baseline associated with a uterine contraction. The deceleration is delayed in timing, with the nadir of the deceleration occurring after the peak of the contractions. (4) Variable deceleration - a visually apparent abrupt decrease (defined as onset of deceleration to beginning of nadir $<30 \mathrm{~s}$ ) in the fetal heart below the baseline. The decrease in fetal heart rate below the baseline is $\geq 15$ beats /min, lasting $\geq 15 \mathrm{~s}$, and $<2 \mathrm{~min}$ from the onset to return to baseline. (5) Prolonged deceleration - visually apparent decrease in fetal heart rate below the baseline. The decrease from the baseline is $\geq 15$ beats $/ \mathrm{min}$, lasting $\geq 2 \mathrm{~min}$, but $<10 \mathrm{~min}$ from onset to return to baseline. (6) Decelerations are defined as recurrent if they occur with $\geq 50 \%$ of uterine contractions in any 20-min segment.

\section{Results}

From January 1, 1985 through December 31, 1999, there were 36117 deliveries at the University of Michigan Hospital. Using the diagnosis of uterine rupture (ICD 9 Codes 665.0 and 665.1) a list of 51 patients was generated. One chart was 
Table 1

Clinical data on 11 patients with uterine rupture

\begin{tabular}{|c|c|c|c|c|c|c|c|c|c|c|}
\hline $\begin{array}{l}\text { Patient } \\
\text { no. }\end{array}$ & $\begin{array}{l}\text { Weeks } \\
\text { gestation }\end{array}$ & $\begin{array}{l}\text { No. of } \\
\text { cesarean } \\
\text { sections }\end{array}$ & $\begin{array}{l}\text { Rupture } \\
\text { location }\end{array}$ & $\begin{array}{l}\text { Fetal- } \\
\text { placental } \\
\text { extrusion }\end{array}$ & $\begin{array}{l}\text { Cesarean } \\
\text { section }\end{array}$ & $\begin{array}{l}\text { Repair of } \\
\text { rupture }\end{array}$ & $\begin{array}{l}\text { Hyster- } \\
\text { ectomy }\end{array}$ & $\begin{array}{l}\text { Hemorrhage- } \\
\text { blood } \\
\text { transfusion }\end{array}$ & $\begin{array}{l}\text { Endo- } \\
\text { metritis }\end{array}$ & Other \\
\hline 1 & 36 & None $^{a}$ & Fundal & Yes & Classical & Yes & No & Yes & No & Enterotomy \\
\hline 2 & 40 & 2 & $\begin{array}{l}\text { Anterior- } \\
\text { extension } \\
\text { to cervix }\end{array}$ & Yes & $\begin{array}{l}\text { Repeat } \\
\text { low } \\
\text { transverse }\end{array}$ & Yes & No & No & No & $\begin{array}{l}\text { Broad } \\
\text { ligament } \\
\text { hematoma }\end{array}$ \\
\hline 3 & 42 & None & Posterior & No & $\begin{array}{l}\text { Primary } \\
\text { low } \\
\text { transverse }\end{array}$ & Yes & No & No & No & No \\
\hline 4 & 41 & 1 & $\begin{array}{l}\text { Anterior- } \\
\text { lateral }\end{array}$ & No & $\begin{array}{l}\text { Repeat } \\
\text { low } \\
\text { transverse }\end{array}$ & Yes & No & No & No & No \\
\hline 5 & 38 & None & $\begin{array}{l}\text { Anterior- } \\
\text { extension } \\
\text { through } \\
\text { cervix }\end{array}$ & No & $\mathrm{No}^{\mathrm{b}}$ & No & Yes & Yes & No & $\begin{array}{l}\text { ARDS }^{c} \\
\text { ATN }^{d}\end{array}$ \\
\hline 6 & 39 & None & $\begin{array}{l}\text { Lateral } \\
\text { through } \\
\text { cervix }\end{array}$ & Yes & Yes & No & Yes & Yes & $\mathrm{Yes}^{\mathrm{e}}$ & No \\
\hline 7 & 40 & 1 & $\begin{array}{l}\text { Anterior } \\
\text { through } \\
\text { cervix }\end{array}$ & Yes & $\begin{array}{l}\text { Repeat } \\
\text { low } \\
\text { transverse }\end{array}$ & Yes & No & No & No & No \\
\hline 8 & 40 & 1 & Anterior & No & $\begin{array}{l}\text { Repeat } \\
\text { low } \\
\text { transverse }\end{array}$ & Yes & No & No & Yes & No \\
\hline 9 & 40 & 1 & $\begin{array}{l}\text { Anterior } \\
\text { into } \\
\text { vagina }\end{array}$ & Yes & $\begin{array}{l}\text { Repeat } \\
\text { low } \\
\text { transverse }\end{array}$ & Yes & No & No & No & No \\
\hline 10 & 29 & 6 & Anterior & Yes & $\begin{array}{l}\text { Repeat } \\
\text { low } \\
\text { transverse }\end{array}$ & Yes & No & Yes & Yes & No \\
\hline 11 & 40 & None & Posterior & No & $\begin{array}{l}\text { Primary } \\
\text { low } \\
\text { transverse }\end{array}$ & Yes & No & Yes & No & No \\
\hline
\end{tabular}

${ }^{\text {a }}$ Prior uterine rupture at 16 weeks' gestation due to motor vehicle accident.

${ }^{\mathrm{b}}$ Diagnosis of uterine rupture immediately after spontaneous vaginal delivery.

${ }^{c}$ Adult respiratory distress syndrome.

${ }^{\mathrm{d} A c u t e}$ tubular necrosis.

${ }^{\mathrm{e}}$ Post-operative pelvic cellulitis. 
missing and not available for review. Of the 50 medical records reviewed, 11 met the criteria for uterine rupture. Therefore, the incidence of uterine rupture at the University of Michigan was $0.03 \%$. The clinical data for these 11 patients are displayed in Table 1. Four of the 11 patients $(36 \%)$ had no uterine scars. Seven of the 11 $(64 \%)$ had one or more prior cesarean sections; one patient (\#10) had six cesarean sections, and one patient (\#1) had a prior uterine rupture at 16 weeks' gestation secondary to a motor vehicle accident. Operative and post-operative complications occurred in seven of the 11 (64\%): (1) hemorrhage requiring blood transfusions in five $(71 \%)$ and a hysterectomy in two (28\%); (2) infection occurred in three (43\%) [post-partum endometritis in two, and post-operative pelvic cellulitis in one]; (3) acute tubular necrosis and adult respiratory distress syndrome requiring admission to the surgical intensive care unit in one (14\%); (4) incidental enterotomy in one (14\%); and (5) broad ligament hematoma in one $(14 \%)$. There were no maternal deaths.
The fetal heart rate abnormalities are displayed in Table 2. Of the 11 patients with uterine rupture, eight of the fetal heart rate monitor strips were available for review. The other three fetal monitor strips, after multiple attempts to retrieve them, could not be found. The descriptions written in the hospital records of the fetal heart rate patterns in these three patients were not detailed enough to adequately classify the fetal heart rate abnormalities. Therefore, these patients were excluded from the fetal heart rate analysis. Seven of the eight $(87.5 \%)$ had recurrent late decelerations, and four of the eight (50\%) had a bradycardia just prior to the uterine rupture. Furthermore, all four $(100 \%)$ of the patients with the fetal bradycardia were preceded by recurrent late decelerations. Prolonged deceleration occurred in one of the eight $(12.5 \%)$, and there was one patient $(12.5 \%)$ with a fetal tachycardia (fetal heart rate $170-180$ beats $/ \mathrm{min}$ ) that preceded the recurrent late decelerations and bradycardia (case \# 2). Only two patients (25\%) had variable decelerations; one with recurrent moderate variable

Table 2

Fetal heart rate abnormalities

\begin{tabular}{|c|c|c|c|c|c|}
\hline Patient no. & $\begin{array}{l}\text { Recurrent late } \\
\text { decelerations }\end{array}$ & Bradycardia & $\begin{array}{l}\text { Prolonged } \\
\text { decelerations }\end{array}$ & Tachycardia & $\begin{array}{l}\text { Variable } \\
\text { decelerations }\end{array}$ \\
\hline 1 & None & None & None & None & None \\
\hline 2 & Yes & Yes & None & Yes & None \\
\hline 3 & Yes & None & None & None & None \\
\hline 4 & Yes & Yes & None & None & None \\
\hline 5 & Yes & None & Yes & None & None \\
\hline 6 & Yes & Yes & None & None & None \\
\hline 7 & Yes & Yes & None & None & Yes $^{\mathrm{a}}$ \\
\hline 8 & Yes & None & None & None & Yes $^{\mathrm{b}}$ \\
\hline Total & 7 & 4 & 1 & 1 & 2 \\
\hline
\end{tabular}

\footnotetext{
${ }^{a}$ Recurrent moderate variable decelerations.

${ }^{\mathrm{b}}$ Mild variable decelerations.
} 
decelerations occurring with the recurrent late decelerations in case \# 7 and one with occasional mild variable decelerations.

\section{Discussion}

As reported in the literature, the most common sign of uterine rupture is a non-reassuring fetal heart rate pattern with variable decelerations that may evolve into late decelerations, bradycardia, and undetectable fetal heart rate [3,4]. In our review of the eight available fetal heart rate tracings, the most common fetal heart abnormalities seen in the $2 \mathrm{~h}$ preceding uterine rupture were recurrent late decelerations $(7 / 8$ or $87.5 \%)$ and terminal bradycardia $(4 / 8$ or $50 \%)$. Only two patients had variable decelerations $(25 \%)$; one was classified as mild and not recurrent, and one had recurrent moderate variable decelerations occurring with recurrent late decelerations (case \# 7). Furthermore, all four cases (100\%) with fetal bradycardia were preceded by recurrent late decelerations. Our data suggest that recurrent late decelerations, not variable decelerations, may be an early sign of impending uterine rupture.

Leung [7] reported on 99 cases of uterine rupture at the University of Southern California. Seventy-eight fetal monitor strips were reviewed with the following breakdown: (1) mild late decelerations in 23/78 (29\%); (2) severe late decelerations leading to prolonged decelerations in $18 / 78$ (23\%); (3) severe variable decelerations leading to prolonged decelerations in $5 / 78(6.4 \%)$; and (4) prolonged deceleration only in $32 / 78(41 \%)$. Their study also showed that late decelerations, not variable decelerations, were the most common fetal heart rate abnormality preceding the prolonged deceleration and uterine rupture.

Rupture of a non-scarred uterus is an uncommon complication. In our study, four of the 11 $(36 \%)$ ruptures occurred in patients with a nonscarred uterus. In the ACOG Educational Bulletin no. 243, January 1998, it is stated that 'uterine rupture may occur spontaneously in obstructed labor, with multiple gestations, with abnormal fetal lie, and especially in women of high parity' [8]. After careful review of the charts, none of these risk factors were present in the four patients. The etiology of the uterine ruptures in these patients is unclear.

Uterine rupture can result in serious maternal and neonatal morbidity or mortality. A question is raised whether there is an association between the severity of the fetal heart rate tracings and the maternal outcome. Maternal complications occurred in five $(62.5 \%)$ of the eight patients with available fetal monitor strips. Two (40\%) of these five had recurrent late decelerations followed by bradycardia, two $(40 \%)$ with only recurrent late decelerations, and one (20\%) with no fetal heart abnormalities. Of the three patients without maternal complications, one had recurrent late decelerations with fetal bradycardia and moderate recurrent variable decelerations, one with recurrent late decelerations and bradycardia, and one with only recurrent late decelerations. There appears to be no obvious association between the severity of the fetal heart rate abnormality and the maternal outcome, but the numbers are small, and no conclusions can be drawn.

Because this was a retrospective review, there are some inherent limitations of the study. A concerted effort was made to obtain all the records and fetal monitor strips, but three of the 11 fetal strips could not be found. The notes describing the fetal monitor tracings in each of the three cases were only brief summaries and not detailed enough to adequately classify the fetal heart patterns. These patients were excluded from the fetal heart rate analysis. However, eight of the $11(73 \%)$ fetal heart rate strips were available for review, revealing recurrent late decelerations in seven and fetal bradycardia in four. The data support the conclusion that recurrent late decelerations and terminal bradycardia are the most common fetal heart rate abnormalities seen in our eight patients with uterine rupture and is similar to Leung's [7] findings.

Another criticism is the small number of patients in the study. In the fifteen-year study period, there were 11 patients with uterine rupture, an incidence of $0.03 \%$. This is comparable to the incidence reported in the literature. Since 
uterine rupture occurs infrequently, it would require a high-volume obstetrical service to generate a large number of patients to evaluate.

In conclusion, the most common fetal heart rate abnormalities observed in our study patients with uterine rupture were recurrent late decelerations and terminal bradycardia. With the exception of Leung, [7] these findings were different than what has been reported in the literature, i.e. variable decelerations [3,4]. In addition, our data would suggest that recurrent late decelerations might be an early sign of uterine rupture. However, since our study population was small, larger studies or reviews would be necessary to further investigate this association.

\section{References}

[1] Donnelly JP, Franzoni KT. Uterine rupture. A 30-year survey. Obstet Gynecol 1964;23:774-777.
[2] Meehan FP, Burke G, Kehoe JT, Magani IM. True rupture/scar dehiscence in delivery following prior section. Int J Gynecol Obstet 1990;31:249-255.

[3] American College of Obstetricians and Gynecologists. Vaginal birth after previous cesarean delivery. ACOG practice bulletin no. 5. Washington DC: American College of Obstetricians and Gynecologists, 1999.

[4] Clark SL. Rupture of the scarred uterus. Obstet Gynecol North Am 1988;15:737-744.

[5] Plauché WC, Von Almen W, Muller R. Catastrophic uterine rupture. Obstet Gynecol 1984;64:792-797.

[6] National Institute of Child Health and Human Development Research Planning Workshop. Electronic fetal heart rate monitoring: Research guidelines for interpretation. Am J Obstet Gynecol 1997;177:1385-1390.

[7] Leung AS, Leung EK, Paul RH. Uterine rupture after previous cesarean delivery: maternal and fetal consequences. Am J Obstet Gynecol 1993;169:945-950.

[8] American College of Obstetricians and Gynecologists. Postpartum hemorrhage. ACOG educational bulletin no. 243. Washington DC: American College of Obstetricians and Gynecologists, 1998. 